\title{
THE MANUSCRIPT LECTURE-NOTES OF ALEXANDER MONRO, SECUNDUS (1733-1817)
}

by

\section{W. TAYLOR*}

THERE RESTS in the Medical School Library of the University of Otago in Dunedin, New Zealand, a unique collection of printed books and manuscripts most of which once belonged to one or other of the three professors each called Alexander Monro, who in succession from 1720 to 1846 occupied the Chair of Anatomy in Edinburgh. I have briefly described elsewhere ${ }^{1}$ the contents of the Monro Collection and how it came to be in Dunedin. This paper has been written in the course of an attempt to achieve two aims. The first of these has been the completion of an annotated hand-list to the Collection; the second and more ambitious is the editing, with commentary, of a set of notes taken down apparently verbatim in 1773/4 from Monro secundus' lectures when he was at the height of his career, and, with Black and Cullen, attracting students from all over the English-speaking world to the Edinburgh Medical School. As I shall show, seven volumes of this set are in the Collection in Dunedin and two are in the Library of the University of Edinburgh $;^{2}$ one I have not yet been able to trace. All the nine extant volumes are corrected and glossed in Monro's hand. The text of the missing volume can, as it happens, be established from other sources, but of course without Monro's comments. The study of these manuscripts and their comparison with other existing sets of notes of his lectures should enable us to get a clearer idea than has hitherto been the case of what exactly he taught at that particular time, and of the evolution of his teaching over a period of almost forty years.

I have traced some fifty sets or part-sets, one hundred and fifty volumes in all. A large number of them are to be found, not unexpectedly, in Edinburgh and in London and these, together with other manuscripts scattered in various libraries in Britain, the items in the Monro Collection in Dunedin and those listed in the National Union Catalogue (U.S.) must surely form the great majority of the survivors. Most of them I have examined in the original or in microfilm. In the case of those to which I have not had such direct access, I have had to rely on strategically chosen "xeroxed" excerpts provided by the kindness of various librarians.

Even a relatively cursory turning of pages amongst this mass of material is sufficient to show that the precise dating of any individual item, essential for the study of

*Douglass W. Taylor, M.D., Professor of Physiology and Associate Dean, University of Otago Medical School, Dunedin, New Zealand.

1 Douglass W. Taylor, The Monro Collection in the Medical School Library of the University of Otago, Dunedin, University of Otago Medical School, 1975.

2 Dunedin, University of Otago Medical School Library (DU:M), Monro Collection M175, 175a, b, 176-9, Edinburgh University Library (EU), MSS Gen.574D and Dk.4.25. 


\section{Texts and Documents}

how Monro's teaching developed, is likely to prove difficult. If I may offer an illustration, MS. 1 (3-7) in the Library of the Royal College of Physicians in Edinburgh (EPH), comprises five volumes of what was fairly obviously an eight-volume set originally. All five volumes have pasted on to the inside of the front board a printed slip, dated 1812, which states that the books are part of the Duncan collection bought in 1772 by Andrew Duncan, senior, ${ }^{3}$ from John Murray, bookseller, in London. The Library contains indeed about seventy volumes thus designated, all of them sets of notes taken from the lectures of well-known Edinburgh teachers. The text bears a striking resemblance to that of a number of other sets the prototype of which seems to be Gen. 569-73 in the Library of the University of Edinburgh (EU). The title-page dates of the latter, 1774/5, can be accepted for good reasons. Each of the five EPH volumes has on a fly-leaf the autograph “A. Duncan 1780". Nevertheless, internal evidence (vol. 6, p. 1747) shows unequivocally that the lectures must have been written down after 1783 , and possibly as late as $1789 / 90$ !

Many manuscripts have of course absolutely no explicit evidence to show either when they were actually written down or the "vintage" of the lectures they record. Others have a title or date which can be demonstrated not to correspond with the material of the lectures and which must be assumed to refer to the time when the student in question copied or somehow acquired that particular set of notes. It is well known that plagiarism of the lectures of the great medical teachers of the eighteenth century was relatively common. Both Boerhaave and Monro primus complained bitterly. The lectures of the latter on comparative anatomy were printed anonymously in 1744 and, as Russell first showed, ${ }^{4}$ Northcote's History of anatomy ${ }^{5}$ is a more-or-less verbatim transcript of the manuscript M166 in the Monro Collection in Dunedin. There was also a flourishing trade in sets of notes copied by professional scribes from shorthand originals. These were in certain cases recopied and repeatedly brought up to date and were held sufficiently valuable to be acquired even by medical practitioners some years after qualifying.

Library catalogues can be of disappointingly little help to the historian in that they all too often accept a fly-leaf date at face value. In a number of cases, indeed, notes from Monro primus' lectures have been attributed to Monro secundus and vice versa. On the other hand internal evidence permitting the attribution of a given set of notes to the course of a particular year is often hard to come by. Monro secundus lectured at a fairly sophisticated level when we bear in mind that he was addressing relatively junior students. He drew in illustration upon his own clinical experience; in matters of theory he expounded the history of the argument and set one authority against another in a way that many of us would hesitate to do today unless the audience were already possessed of a considerable acquaintance with the subject. It is these things that make his lectures still interesting to read. But he very seldom gives a precise date and equally seldom mentions a precisely datable fact in such a

- For Andrew Duncan, the elder (1744-1828), physician and professor at Edinburgh University, see Dictionary of national biography, London, Smith Elder, 1909, vol. 6, pp. 161-162.

'Kenneth F. Russell, British anatomy 1525-1800. A bibliography, Melbourne University Press, 1963, pp. 166-167 and 174-175.

- William Northcote, $A$ concise history of anatomy from the earliest ages of antiquity, London [printed for T. Evans], 1772. 


\section{Texts and Documents}

way that we can infer the date of his statement of that fact.

There is another problem. Members of a particular class taking notes from a lecturer in the usual way will not all write down the same thing; some will omit or alternatively emphasize here, some there. Only where two students have succeeded in taking down a lecture verbatim will the results appear identical. The converse however does not hold, and repeated copying with minor degrees of updating quite apart, the finding of apparently identical and verbatim notes may indicate not that the writers were members of the same class but rather that the lecturer changed his material only slowly, reading for years at a time from the same prepared text. Despite what was said by his son, ${ }^{6}$ we shall see that this latter explanation cannot entirely be disregarded in Monro's case.

Some of the surviving manuscripts are scrappy in the extreme, comprising little more than quickly jotted headings and notes and of small value for any study of Monro's teaching; others contain only a rather small number of lectures. Increasing familiarity shows, too, that resemblances are such as to permit a rough division into groups, the differences between which are so great as to make detailed textual comparison quite unnecessary. In any one group however the mass of material is large enough to make the task of comparison sentence by sentence from first page to last daunting in the extreme; it was indeed impossible in the time at my disposal. And so in preparing the following commentary I have paid particular attention to (i) the number of lectures in the course and the order in which they were delivered; (ii) the rather few datable statements which experience has taught me to look for; (iii) wordby-word comparison of from ten to twenty passages originally chosen at random and varying from one to fifteen or twenty pages (a whole lecture) in length.

Let us consider first those sets of manuscripts that are either complete or nearly so. The Dunedin (DU:M) manuscripts N175, 175a, 175b and 176-179, together with EU Gen.574D and EU Dk.4.25, form nine volumes of a ten-volume set all written in the same hand, reliably dated, and all corrected by Monro secundus himself. Vol. $3\left(\mathrm{ft}^{\mathrm{r}}\right)$ has in Monro's hand: "Best copy of the lectures of Dr. Monro $2^{\text {dus". }}$. The Cole Library in the University of Reading (RU) contains a four-volume set (MS. No.1628) which is complete and bears the same date as M175-179. Extended comparison demonstrates its virtual identity with the Dunedin set, although Monro's corrections are of course lacking, and minor differences of wording suggest that the two were made independently. If we accept this identity and then compare the text of Lectures 47 (not 46, as Monro tertius would have it!) and 48 in RU Cole No.1628 with the printed text in the Essays, pp. 3-25, and bear in mind that the printed passages were almost certainly corrected by Secundus and edited by Tertius, we find again virtual identity. ${ }^{7}$ The corresponding lectures have been cut out of DU:M M175b and we can hardly fail to conclude but that Tertius did so as the shortest way of getting copy to the printer! It is stated in the Essays that "This extract is taken from

\footnotetext{
- Alexander Monro tertius, Essays and heads of lectures on anatomy, physiology, pathology, and surgery. By the late Alexander Monro, M.D. With a memoir of his life, and copious notes explanatory of modern anatomy, physiology, pathology, and practice. By his son and successor, Edinburgh, Maclachlan, Stewart \& Co., 1840 , p. viii.

? Ibid., p. 3.
} 


\section{Texts and Documents}

a manuscript copy of lectures written by Mr. Thorburn during Session 1773-4".8

It is important to be clear about the identity of Mr. Thorburn. Some confusion has been generated by Tertius' statement in the Memoir of his father which precedes the Essays where he writes ". . . he never used notes, and indeed, possessed, for many years, heads only of his lectures. . . . During 15 years he lectured from heads of his lectures, the arrangement of which he repeatedly altered. . . . He was at length relieved of this embarrassment by purchasing from Mr. Thorburn, who became his pupil in 1775, a copy of his own lectures". 'Wright-St. Clair accepts this statement and identifies DU:M M224-41 as the notes in question. ${ }^{10}$ Furthermore, two sets of notes in the Library of the Royal College of Surgeons of England (LS), 42.a.49-55 and 42.a.62-3, purport to be also from Thorburn originals. The first of these has (42.a.49, f5') "The copy of Dr. Monro's Lectures from which this is transcribed was taken down in shorthand in his class by Mr. Thorburn of Edinburgh about the year 1773; but it has since been corrected by different hands-1783"; the second has (42.a.62, t.p.) "Lectures on Surgery by Alexander Monro M.D. transcribed from the copy of his lectures as taken down by Mr. Thorburn in the year 1776 with additional observations delivered during the years 1781-, 2-, 3- and 4, by James Curry." The matter is even further confused, however, by two other passages in the Essays. On p. 3, as we have already seen, the quoted extracts from Lectures 46 (i.e. 47) and 48 are said to be from Mr. Thorburn's notes 1773/4, and on p. 109, Secundus in a quoted passage writes of notes of his lectures taken by Mr. Thorburn in 1770, a statement which is repeated in a letter to Mr. Wood, written in $1807 .{ }^{11}$ However, what we must regard as unassailable evidence about the origin of DU:M M175-9 is provided by Secundus himself in the Appendix to his Observations on the muscles and particularly on the effects of their oblique fibres, published in 1794 as part of his controversy with Gilbert Blane. ${ }^{12}$ On pp. $39-40$ he writes as follows:

In the years 1769 and $1770 \mathrm{Dr}$. Gilbert Blane attended my Lectures: and in the last of these two years Mr. Thomas Thorburn did so: He likewise attended my lectures in 1773. About the same period, Mr. Thorburn attended several of the other Medical Professors, and wrote down their as well as my Lectures, which, for a number of years afterwards, were copied and sold, or lent out to be copied by students. And on the lowest computation, that twenty copies of my lectures have since that time been written annually by the students, there must now be extant more than

Ibid., p. 3, footnote.

- Ibid., p. viii. Against the second of these three assertions we must set the testimony of Benjamin Rush that "[Monro] speaks with great propriety and as he commits all his lectures to memory he embellishes them when speaking with all the graces of elocution." From Journal commencing Augst 31st, 1766 by Benjamin Rush, EU Dk.2.18, f70, (being a transcript of microfilm M.28. The original is in Indiana University Library.) This remark seems to argue Monro's dependence on more than just heads of lectures.

${ }^{10}$ Rex E. Wright-St.Clair, Doctors Monro. A medical saga, London, The Wellcome Historical Medical Libary, 1964, p. 77.

${ }_{11}$ Copy of a correspondence between Alex Monro, Sen., M.D. Professor of anatomy and surgery, and Mr. William Wood, Surgeon, Edinburgh, Murray \& Cochrane, 1807. The letter in question is dated Edinburgh, 15 April 1807, and runs: "... a Mr. Thorburn who had written in shorthand notes from my lectures in the year 1770 of which many copies have been circulated".

12 Alexander Monro secundus, Observations on the muscles and particularly on the effects of their oblique fibres: with an appendix in which the pretension of Dr. Gilbert Blane that he first demonstrated the same effect to be produced by oblique muscles as by straight ones, with a less proportional decurvation of fibres, is proved to be unfounded, Edinburgh, [printed for J. Dickson \& $\mathrm{E}$. Balfour], 1974. 


\section{Texts and Documents}

four hundred copies of them; for they have been handed down to this time with fewer corrections and additions than might have been expected.

On the 8th of November 1774 I purchased a copy of Mr. Thorburn's manuscript, written in ten volumes, by Mr. John Wilson, who, from being lame, had the conceit of calling himself Claudero and was best known by this name.

He subscribes the last page of the last volume in the following words: FINIS. Edinburgh, April 29. 1774. Claudero Scripsit.

I found that Mr. Thorburn who had no knowledge of Anatomy when he began to write my Lectures had not attempted to write my demonstrations or descriptions of the parts; neither had he attempted to copy any of the figures which, in this and in many other parts of my course I have been in the custom of drawing with chalk upon a black board, in order to render my Lectures more intelligible to the students. In consequence of this, his notes are particularly imperfect wherever the lecture is connected with figures. Keeping this in view let us next read what he has written.

These last few lines make it absolutely certain that we are dealing with DU:M M175-9, vol. 10 of which, in Edinburgh, has on its final page the words which Monro quotes. But if further proof were needed the extracts which follow (pp. 39-43) are identical with passages marked in pencil in vol. 2 (M175a) of the Dunedin set. Nevertheless we are still faced with a problem. Secundus in his Observations of 1794 states that Thomas Thorburn in fact attended his lectures twice, in 1770/1 and 1773/4, and implies that he took notes in shorthand on both occasions, the earlier MS. being in 1794 in the possession of his son John Thorburn, then a student in Edinburgh, the other being that used by John Wilson "Claudero". He quotes (pp. 45-49) a number of passages from the former, ending with the words "Transcribed from the original manuscript lectures taken in shorthand by Mr. Thomas Thorburn in 1770, by me, his son. John Thorburn, Edinburgh, December 27, 1792."

The lectures from which this second group of excerpts is said to be transcribed do not correspond in subject matter to those of the same numbers in M175-9, and the actual wording is found to be appreciably different when the appropriate lectures are compared.

However, while in face of all this we may with some justification dismiss Tertius as a poor historian, it is more difficult to ignore the fact that the largest group of surviving manuscripts comprise what the evidence compels us to regard as different recensions of not the $1773 / 4$ but the 1774/5 text.

There are a number of MSS. in which, depending on their completeness, all or most of the following statements occur:

Lecture 4: “. . . the late Mr. Hewson ..." (Hewson died in May 1774).

Lecture 95: "... [a dental instrument] which a gentleman who attended here last winter was so obliging as to give me."

Lecture 98: "As I've got a fresh subject that I may operate upon the eye in the most entire situation possible I shall next proceed to the operation for the cataract." (This in a lecture that started off by discussing lithotomy.)

Lecture 102: ". . . [of a hydrocele] a very interesting case that occurred here 3 years ago in which Dr. Cullen, Mr. Wood and I were consulted."

Lecture 106: (in an account of mortality rates following mastectomy) "I began in the year 1766 ... and the last patient who is alive was operated on 2 years ago."

Lecture 107: (on recovery of the apparently drowned) " . . . a very excellent paper published this winter by Dr. Cullen on this subject."

The first of these clearly imposes a restriction and could at the earliest refer to the 


\section{Texts and Documents}

$1774 / 5$ session; the next four could not be repeated in any lecture-course other than that of a particular year without anachronism; the last, if the date can be established, should serve to fix the whole series. These statements are to be found in EU Gen.56973, in DU:M M224-41, in EPH M.10, 59-62, in MS. 67880-66 in the Library of the Liverpool Medical Institution (LvM), and in LS 42.a.49-55, which, as has been mentioned, derives ostensibly from a Thorburn original.

Cullen's paper or rather letter is dated 8 August 1774 but the title-page carries the date 1776. ${ }^{13}$ However, quite apart from the fact that Monro must already have had a good idea of his views since Cullen acknowledges his help (p. [15]), there is evidence that these views may have been published, in Monro's sense of the word, early in $1775,{ }^{14}$ so that the reference could have been given in the $1774-75$ lecture-course, the lecture in question being delivered in early April. The date 1774 is corroborated by the sets EU Gen.569-73 and EPH M.10, 59-62. The first of these is complete. The title-page of each of the first three volumes bears the date 1775 ; vol. 1 has as colophon "End of the First Volume, The end of the ostiology 1.1.1775", which since it was a Sunday, must have been the date on which the student finished copying out his notes; vol. 4 has Dr. Monro's Surgery 1775, April 1775; and vol. 5 has 1774-to 1775. All have the book-plate of James Johnson Surgeon Lancaster and were presented by his grandson Christopher "to his former pupil William Turner April 6th 1869". Vols. 1-3 are written in a different hand from vols. 4 and 5. The latter two, comprising mainly the surgical lectures, were written by the same person who wrote two other MSS. in the University Library; EU Dc.1.49 Dr. Cullen's practice of physic ends "Scriptum per me J. Johnson Baikhouse the 5th of September A.D. 1775.", while Dc.10.1 has on $\mathrm{f} 2$ "Chymical Lectures by Dr. Joseph Black Professor of Chemistry in the University of Edinburgh A.D. 1770. James Johnson Edinburgh December 10th 1774 finished Jan 8th per me J. J. Jacobus Johnson". A note by Christopher Johnson reads "Copies of Lectures, taken on the spot in shorthand by James Johnson . . .". Johnson's name appears on the medical matriculation lists for 1774 and 1775. The EPH set is incomplete, lacking vols. 3 and 4 and, fairly clearly, a seventh volume.

\footnotetext{
18 William Cullen, A letter to Lord Cathcart, President of the Board of Police in Scotland concerning the recovery of persons drowned and seemingly dead, London, J. Murray, 1776.

16 The business of dating Monro's statement about Cullen's letter is crucial but by no means simple. The letter itself is dated Edinburgh 8 August 1774 and was published along with an Extract from the Journals of the Board of Police, Aug. 11, 1774. This states that Lord Cathcart presented the letter and a paper to the Board which then ordered that they be printed and distributed. Then in Medical and Philosophical Commentaries by a Society in Edinburgh Volume Third, Part II, London, 1775, there is a reference to the Extract and to Cullen's letter with the statement (p. 211) "Of the letter from Dr. Cullen . . . we propose to give a full account in a future number". From internal evidence Part II was published in late April or May 1775, and Cullen's letter must by then have been published in the literal sense of being brought to public notice. An examination of the firmly-dated 1773/4 notes does not help much. The statements about Hewson, Cullen, and the dental instrument are naturally lacking. Operations on the eye come first in the surgical section, because these are the tissues most liable to be changed with time. On mastectomy we read (DU:M M177, p. 1519): "I have kept a regular account of the cases where every circumstance was known since the 1767. Fifteen persons of fashion have had the mamma exstirpated besides one or two only lately ...". Finally, (DU:M M176, p. 1368) "A case I attended last winter was very instructive". This must refer to the winter of 1772. If Lecture 107 was given in early April " 3 years" could mean in fact either two and a half years from April 1775 or three and a half years from 1776. I think the balance of the evidence points to the earlier date. Wellcome MS 3619 has "about 3 years ago".
} 


\section{Texts and Documents}

The style of writing changes abruptly after lecture 88 in vol. 5 . All are inscribed in yet a third hand, "Dr. Jas. Hamilton Junior". The title-pages of vols. 1, 2 and 5 have "Winter 1774/5". The LvM manuscript carries " 1774 " boldly on the title-page on vol. 1, while the Dunedin set is undated. These four, and basically also LS 42.a.4955 , must be regarded as records original or copied of one and the same lecture-course. All of them have the same number of lectures in the same order and wherever the first four have been compared they are found to be word-for-word the same apart from the occasional inversion, substitution of singular for plural-or vice versa-and scribal slip leading to nonsense in one of the texts. The LS manuscript differs a little more, in keeping with its somewhat chequered history. All contain all of the key passages listed earlier. To suppose them different is to claim that Monro repeated his lectures, word-for-word, complete with anachronisms. The number and pattern of the lectures is different from that in the text of 1773/4.

Let us now return to Mr. Thorburn. There is really no evidence for Tertius' statement that Mr. John Thorburn became his father's pupil in 1775, even though it is not explicitly contradicted by his reference a little later to "Mr. Thorburn" in 1773/4. A John Thorburn does appear in the matriculation lists for 1772 and 1773, and again in those for 1791, 1792 and 1793. The latter was without reasonable doubt the son of Thomas Thorburn. Of the former we have no knowledge, but surely Secundus' references to Thomas Thorburn must be taken at face value. Tertius was, after all, writing half a century after his father's appeal to the Thorburn evidence. It is of some interest that the late Professor F. J. Cole, while accepting the dates on his manuscript (1773/4), assumed that it was a copy of the text which according to Tertius was bought back by his father for $£ 5.15$

However, a number of points remain obscure. Why, for example, is LS 42.a.49-55 said to derive from a Thorburn original, and what are we to say about the status of the Dunedin set M224-41? In fact Thomas Thorburn matriculated every year from 1770 to 1775 inclusive. We know that he must have been an accomplished writer of shorthand who doubtless made a good thing out of it and there is no inherent reason why those manuscripts dated 1774/5 should not represent a third Thorburn transcription. The date "1773" on LS $42 . a .49$ does not claim to be other than approximate. That of " 1776 " on LS $42 . a .62$ is clearly suspect.

The Dunedin set M224-41 presents a more difficult problem. It represents the text of $1774 / 5$. It has been corrected over a long period by Monro-one substantial correction is dated 1789, and another cannot be earlier than 1794. In an original twenty-three-volume format (four volumes are missing from the Collection) with much unused paper it can hardly have been the type of thing a student would sell in the market-place. It represents much the commonest surviving and thus presumably the most popular recension and yet its relation to Monro's teaching is by no means clear. Although he has corrected it, the anachronistic passages remain and the corrections do not appear even in such late but virtually identical manuscripts as those

\footnotetext{
${ }^{16}$ RU Cole No. 1628 has on f1v "These notes were taken by John Thorburn a pupil of Monro secundus. Monro did not write out his own lectures and purchased Thorburn's notes for $£ 5$... [Signed] F. J. Cole." I think there is no doubt that Cole simply accepted Tertius' statement (Essays, op. cit., note 6 above, p. viii).
} 


\section{Texts and Documents}

written by Sir James McGrigor in 1790/1 ${ }^{16}$ and by Samuel Hughes, sr., in 1792.17 Unfortunately both these lack the surgical lectures and thus the important "dating" phrases. Only the notes made by Tertius from his father's lectures in 1793 (DU:M M242-4) incorporate some but not all of the corrections. Why is there no real evidence for the continued use by Monro of the Thorburn set of 1773/4, purchased for the then sizeable sum of $£ 5$, apparently to relieve him from difficulties arising from lack of a fair copy? Of the manuscripts known to me, only RU Cole No. 1628, an unnumbered MS. in the Royal College of Surgeons, Edinburgh, dated 1775/6, the undated EU Gen.579 containing only Lectures 1-28 and a 2-vol. MS. by one J. Pennington in the Royal Army Medical College, dated 1778, correspond to M175-9, and the second of these must certainly have been copied, because the appended dates are not possible lecture-dates for that session. Perhaps the most plausible hypothesis is that Monro secundus had M224-41 copied, and later altered the text at leisure but incompletely, to be of use to the son whom he hoped would succeed. There is certainly evidence in the shape of scattered comments in Tertius' hand that they were used by him.

The most striking impression that follows the reading of any set of notes of lectures later than $1774 / 5$ is their very obvious similarity to what we must now regard as the established text of that course. Two sets of manuscripts, EU Dc.3.35-40 and EPH 1.(3-7), the latter lacking vols. 1-2 and an eighth volume, have exactly the same lecture order, and are, over long passages-many pages at a time chosen randomlyprecisely the same as for example EU Gen.569-73. They differ however in the wording of the key passages to which I have alluded earlier. Both refer simply to "a very excellent paper on the subject by Dr. Cullen", to a "very extraordinary case that occurred here a few years ago in which Dr. Cullen, Mr. Wood and I were consulted", and to a dental instrument "which a gentleman who attended here some years ago was so obliging as to give me". Both contain immediately after the passage on the statistics of breast cancer (Lecture 106) an additional section which reads "in the year $1783 \mathrm{I}$ had seen 37 patients of this disease on whom the operation was performed and out of that number 18 after 3 or 4 years were free from the complaint". In neither case is the addition in the form of an intrapolation but is part of a continuous and unblemished text. Obviously these manuscripts must be dated after 1783 . The passages are also found in MS. 3618 in the Wellcome Institute for the History of Medicine which can reasonably be taken to refer to session $1789 / 90 .{ }^{18}$ We must therefore ask did Monro after 1774/5 simply use the text of that session's lectures, bringing it up to date from time to time, but largely repeating it word for word, as

16 For Sir James McGrigor M.D. (1771-1858), army surgeon, see Dictionary of national biography, 1909, vol. 12, pp. 546-549. McGrigor's notes of Monro's lectures, in four volumes, are in the Library of the Royal Army Medical College. Some of the lectures give not only the date but the day of the week and the hour, and can hardly be other than a contemporary record. Unfortunately they lack the surgical lectures and thus the "dating" statements. I am indebted to Maj./Gen. A. MacLennan for help with this and the Pennington MS (see below).

${ }_{17}$ For Samuel Hughes, sr., see MS. 10a-188 in the Library of the College of Physicians, Philadelphia (PPC), which has this statement (f 2 v): "The following lectures were written in Edinburgh by my father during the winter of 1792 and 93-he having accompanied me during the first winter of my studying . . . He was 60 years of age. [Signed] Saml. Hughes Jnr."

18 Wellcome MS. 3618 ends with the words: "Finis voluminis secundi William Rae 23rd Feby 1790". Rae matriculated in Edinburgh from 1789 to 1791. 


\section{Texts and Documents}

Tertius might seem to imply; ${ }^{19}$ or did the $1774 / 5$ text seem so good and prove so popular that it became the basis of the flourishing trade that we know to have existed in sets of lecture-notes, the up-dating being done by students as might be inferred from Secundus' earlier-quoted remarks? ${ }^{20}$ It is difficult to believe that the changed wording of crucial passages and other minor but not negligible additions could have come from anyone other than Monro himself and they certainly ring true. On the other hand one or two clearly anachronistic passages remain which one hesitates to attribute to Monro. It seems to be stretching the arm of coincidence rather far that EU Gen.569-73 and EPH M10.59-62 on the one hand and EU Dc.3.35-40 and EPH 1.(3-7) on the other should all say in Lecture 98 "As I have got a fresh subject that I may operate on the Eye in the most entire situation possible I shall next proceed to the operation for the Cataract", when there must be at least a decade and probably fifteen years between the two pairs. The impression conveyed very strongly to the reader of these various groups of lecture-notes is one of virtually complete identity, an impression different from that gleaned from reading notes of lectures by Monro primus, which can safely be allotted different dates. The language of the latter is remarkably uniform but they have nevertheless those little variations in the precise wording of anecdote that suggest something approaching the total recall of the psychologists rather than the repeated reading of an unaltered text.

There is a fourth group of manuscripts, the dates of which can fairly be put earlier than 1773 and which present a number of problems. None of those $I$ have seen is complete and verbatim in the sense of the EU Gen.569-73 or DU:M M175-9 sets (the latter as always including the two Edinburgh vols. 5 and 10 but admittedly lacking vol. 4). They exhibit apparently complicated inter-relations.

One of the most interesting of these earlier examples is undoubtedly that in the Royal (Dick) School of Veterinary Studies, Edinburgh (EVC MSS.1-2). A third volume is obviously missing but its index has been bound in with vol. 2, and thus we know the outline of the whole course. In the first instance it contains the only copy I have seen of Monro secundus" "History of anatomy" as he gave it during his earlier years as a teacher. Later he was at pains to point out that he had truncated it considerably to make room for the practical part of the course. This section of vol. 1 can be dated on internal evidence (ff 47,51 ) as $1763 / 4$. The remainder of the text in which the lectures are numbered from 1-87 (pt.)-it is almost entirely the surgical lectures which are missing - cannot have been started earlier than the end of 1766 (f266). The hand is, interestingly, the same as that which wrote DU:M M175-9 and EPH M10.59-62, namely that of John Wilson, "Claudero". The text is less than verbatim and does not include every lecture. This is evident from the rather staccato style and the footnote on f51 (117) which reads "N.B. The intermediate lectures pro-

10 Essays, op. cit., note 6 above, p. viii.

${ }^{20}$ See note 12. We ought also to take into account the fact that Monro secundus also quotes in the Observations (pp. 49-52) three extracts from each of two other manuscripts which he says belonged respectively to James Russell and Benjamin Bell, both well-known Edinburgh surgeons. The first, he says, purchased his copy in 1775 or 1776 while "Mr. Bell has had his copy about six years in his possession". The words of each were the same and Monro printed only the one set of extracts, attaching two different page numbers to each. We can only conclude either that Bell thought it worth while to purchase a copy of the $1774 / 5$ course presumably because there had been little change or that he indeed bought a more recent revision, but it did not differ greatly from the earlier text. 


\section{Texts and Documents}

ceeded to explain the Bones of the Face with their connections, processes, Holes \& etc. but being so fully treated of in Monro's Osteology they are omitted. Likewise what other lectures shall appear missing it may be concluded they are wholly demonstrative and consequently to be met with in almost every anatomical writer." There is virtual identity between this set and the manuscript LS 276.g.66-73, and also between it and the manuscript EPH "Goodsir", in the few lectures in which they overlap and from the evidence of the index to vol. 3 pasted in to EVC MS 2. The set LS 276.g.66-73 is uniformly bound in eight rather slim volumes but has been very untidily put together. The writing is mainly on the rectos with annotations from time to time on the facing versos, but sometimes, e.g. in 276.g.70, we find that the volume has been reversed and turned upside down. To my eye at least, four different hands are involved and a fifth has been responsible for the annotations and the indexes, and also for Lecture 110 in vol. 8. Vol. 2 has "Index to serve for my notes which I endeavour to place in as much order as possible." [!!] Vol. 7 (p. 30) has the statement "The following operations were by Dr. Monro introduced into the body of Anatomical lectures by us subjoined here." Apparently the description of lithotomy in women in fact began Lecture 36. Allowing for this, the order up to Lecture 87 is exactly the same as that of EVC MSS. 1-2 and the wording of the text must be regarded as the same. Where EVC MS. 2 and EPH "Goodsir" overlap (i.e. Lectures 80-87) they too are the same. "Goodsir" continues to the end of the course and it and the relevant parts of LS 276.g.66-73 are again virtually identical.

Goodsir's manuscript is dated 18 May 1770. Monro's course seems to have finished as a rule at the end of April or the very beginning of May, and the date, together with the uniform style of writing and ink which are in contradistinction to the minor differences we would expect in notes taken direct, day-by-day, point to the manuscript having been written more or less at leisure from a copy-an impression given by so many of these manuscripts. Goodsir was a student from 1768-70 and it must have been very unusual for students to take Monro's class-at least for the first time-so late in their careers as May 1770 might indicate. Goodsir attended Francis Hume's clinical lectures in the summer of 1769 , and Cullen, if not Hume, made it quite clear that he expected students to know their anatomy before they came to him. ${ }^{21}$ Furthermore, the text of the surgical lectures in Goodsir is not at all like that of EU 575D which is dated 1770 and which internal evidence-a reference to the Baron de Wenzel's visit to Edinburgh "last summer" (i.e. 1769) 22 to demonstrate his operation for cataract-shows are indeed notes of the surgical lectures of 1770 .

The manuscripts LS 276.g.76-7 are two rather scrappy notebooks uniform with LS 276.g.67-73 and written in the same mélange of hands. Both have on the inside

\footnotetext{
21 John Thomson (editor), The works of William Cullen, M.D., 2 vols., Edinburgh \& London, William Blackwood \& T. \& G. Underwood, 1827. The passage in question (vol. 1, p. 10) is interesting: “. . . the human body is a machine that must be governed by the laws of matter and motion that affect every part of nature; and therefore to the understanding of it some of the principles of natural philosophy are very necessary. ... The knowledge of chemistry as far as it concerns the nature of the body and of the fluids will likewise be necessary; but especially the knowledge of anatomy must everywhere accompany our present study, and I must suppose you all instructed in that respect. for if you are not, it will be impossible to supply it."

${ }^{22}$ The Caledonian Mercury, Edinburgh, Wednesday, 3 May 1769 [Num. 7299] and also Saturday, 20 May 1769 [Num. 7305].
} 


\section{Texts and Documents}

of the front board "Monro by Swan" and 77 contains the phrase "Loose notes from Saunders worth consideration", the two phrases being in the "fifth" hand of LS 276.g.66-73 above. The Edinburgh matriculation lists show that James Saunders enrolled in 1765-67 and Wm. Swann in 1766-69. In the absence of positive contrary evidence a guess would be that the set 276.g.66-73 was written by Swann in 1767 or 1768 and acquired and added to by its latest owner a year or two later.

The relationships and most likely date of this group of manuscripts having been reasonably established, it can be said that the notes made by G. R. Brown of Maryland ${ }^{23}$ (the 2-vol. MS. is in Dunedin but is not part of the original Monro Collection) provide a somewhat expanded but essentially similar text to that just discussed. It was written certainly after 1766 and the t.p. date 1767 can be accepted.

Three other manuscripts seem to be clearly related to each other-EPH M.9.24 and M.9.21-3, and EU Dk.4.24. The first has on its fly-leaf "Ex libris Jo:Moncrieff 1776", the second has ". . . Lectures delivered by Dr. Alex Monro . . taken down by Tho. Davison student of Physiology anno domini 1770 and 1771", and the last is undated. I think that internal evidence points to these being composite volumesM.9.24 may be an exception-of uncertain vintage, in part at least earlier than 1766 . EPH M.9.24 omits the history of anatomy and the comparative anatomy, but apart from this, seems to cover the course. The hand is neat and uniform throughout and the prose is continuous, both features pointing to a copy made at leisure rather than in the class-room. A number of gaps in the text suggest that the copyist had some trouble in deciphering his original. There is certain proof of mis-binding on pp. 204 213. Internal evidence (p. 282) shows that the lectures were given after 1763. The statement on p. 367, "But I shall refer you to Dr. Whyte professor of the theory of Physic for the more beautiful and curious circumstances" could hardly have been made after Whytt's death on 18 April 1766, and it would be reasonable to put the date at $1765 / 66$. The name "Gul. Moncrieffe" appears in the graduation list for $1768^{24}$ and it is tempting to see him both as the writer and elder brother of the eventual owner, although there is of course no proof.

The manuscript EU Dk.4.24 bears the crest of John S. Pakington. The library catalogue gives the date as ? 1776 but this is on account of the water-mark which is neither here nor there as far as dating the actual text goes. The order and the wording are the same as those of EPH M.9.24 except for the last section which is exactly the same as the "added" Lecture 110 in LS 276.g.73, and so the reference to Whytt does not appear. The handwriting and the ink are extremely uniform, again suggesting a copy made at leisure.

The Davison set, EPH M.9.21-3 is harder to unravel. The text is divided into topics and not lectures. The second volume of the three contains the surgical notes. In vol. 1, on pp. 91-92, thirteen lines have been scored out. This is because they are a repetition of fourteen lines which have already appeared on $\mathrm{pp}$. 83-84. The manuscript thus can hardly represent lectures taken down in class, despite what the title-

${ }^{23}$ For Gustavus Richard Brown, see Wyndham B. Blanton, Medicine in Virginia in the eighteenth century, Richmond, Garrett \& Massie, 1931, pp. 130, 310.

${ }^{24}$ For Moncrieffe and other Edinburgh graduates, see Nomina eorum qui gradum medicinae doctoris in Academia Jacobi Sexti Scotorum regis quae Edinburgi est, adepti sunt. Ab anno MDCCV ad annum MDCCCXLI, Edinburgh, 1846. 


\section{Texts and Documents}

pages may be thought to imply. Large parts, but by no means all of the text, are the same as EPH M.9.24. For example, the text of vol. 1, pp. 53-78, is identical with that of M.9.24, pp. 1-44. The order then diverges, but p. 166 and M.9.24, p. 45 are again the same. The writer seems to have had the same difficulty with his original as shown by the blanks. Thus on pp. 105-106 we find "The valvular-said to receive the lymphatic artery or to be the continuation of it and-form a red vein and also to inhaler now instead of this we-Branches as before supposed into the cavities and there-quantity of liquor that transudes the inorganic pores of the parts."

The corresponding section of M.9.24 has "The valvular-said to receive the Lymphatic artery or to be the continuation of it and-form a red vein and also to inhale now instead of this we-Branches as before supposed into the cavities and therequantity of liquor that transudes through the inorganic pores of the parts".

The text of the surgical notes differs appreciably from M.9.24 as does the ordering of the topics. Vol. 3 contains notes of comparative anatomy; the physiology, while obviously similar, is by no means the same as the corresponding section of M.9.24 and does not include the reference to Whytt; and finally there is in a different ink on pp. 79-80, 90-96 and 153-157 an "aberrant" lecture on the uterine vessels, presumably inserted later, the text of which is identical with the corresponding lecture in EPH MS. "Goodsir". It seems best to suppose that Davison acquired what Sylas Neville might have regarded as a "tolerable copy of Monro's lectures" 25 based upon but brought up to date from, the text of M.9.24, which, as we have already seen, can probably be dated session 1765/6.

What then does it all add up to when an attempt is made to order the material so as to assess the evolution of Monro's teaching over forty years? It can be said with some confidence that the G. R. Brown manuscript in Dunedin is the best source for Monro's teaching in his first decade; that the Thorburn transcription of 1773/4 (the seven volumes in Dunedin and the two in Edinburgh all corrected by Monro himself, with the deficiency made up from RU Cole No. 1628) provide an apparently verbatim version of the course, if we accept the absence of illustrations, as it was delivered near the peak of Monro's career; that this version should be carefully compared with that of the following year ${ }^{26}$ and that, finally, the evidence points to but little change in content over the next eighteen years until we come to the notes of Tertius written in 1793 (DU:M M242-4) and 1796 (DU:M M246-7), which are rather rough, extremely untidy, and cover only about one-fifth of the course, but which do apparently contain some new material.

The preparation of such a "comparative" edition of the Thorburn text is a task to which I hope shortly to address myself.

${ }^{25}$ Basil Cozens-Hardy (editor), The diary of Sylas Neville, 1767-1788, London, Oxford University Press, 1950, p. 151. The passage is amusing and reads thus: "Mon. Mar. 9th Friend Knowles offered to procure me the use of a tolerable copy of Monro's lectures if I would get two copies transcribed and give him one. This would be a dear copy indeed."

26 Other more or less complete examples appear to be LvM 67880-69, and PPC 10a-90 and 10a-91. LS 42.a.62-63 contains only the surgical lectures, and although it claims to be derived from Thorburn's shorthand copy the "dating" statements have been changed so as to give no clue and collection of statistics on mammary cancer is said to have started in 1776! 
SUMMARY

Notes taken by students at various times from the lectures of Alexander Monro, secundus (1733-1817) exist scattered in various libraries. As many as possible of these manuscripts have been examined, dated, and compared with each other prior to attempting to assess how his teaching developed throughout a long career during which he and others attracted generations of students to the Edinburgh Medical School.

Of particular value in such an assessment are two sets of notes in the Monro Collection in Dunedin, New Zealand, both corrected by Monro himself. Neither set is complete, but two missing volumes of one are now known to exist in Edinburgh, and the remaining gaps can be appropriately filled.

\section{ACKNOWLEDGEMENTS}

I am indebted to many librarians for microfilms and xerox copies, but I should especially like to thank Mr E. Cornelius, Librarian, Royal College of Surgeons of England; Miss Joan Ferguson, Librarian, Royal College of Physicians of Edinburgh; Mr C. P. Finlayson, Keeper of Manuscripts, Edinburgh University Library; Mr E. Freeman, Librarian, Wellcome Institute for the History of Medicine; and Miss D. Wardle, Librarian, Royal College of Surgeons of Edinburgh; with all of whose collections I worked for extended periods and for whom and whose staff no amount of trouble was too much. 